\title{
Atmospheric fate of two relevant unsaturated ketoethers: kinetics, products and mechanisms for the reaction of hydroxyl radicals with $(E)$-4-methoxy-3-buten-2-one and $(1 E)$-1-methoxy-2-methyl-1-penten-3-one
}

\author{
Rodrigo Gastón Gibilisco ${ }^{1}$, Ian Barnes ${ }^{1, \boldsymbol{t}}$, Iustinian Gabriel Bejan ${ }^{2,3}$, and Peter Wiesen ${ }^{1}$ \\ ${ }^{1}$ Institute for Atmospheric and Environmental Research, Bergische Universität Wuppertal, 42097 Wuppertal, Germany \\ ${ }^{2}$ Faculty of Chemistry, Department of Chemistry, Alexandru Ioan Cuza University of Iasi, 11 Carol I, Iasi 700506, Romania \\ ${ }^{3}$ Integrated Centre of Environmental Science Studies in the North Eastern Region, Alexandru Ioan Cuza University of Iasi, \\ 11 Carol I, Iasi 700506, Romania \\ $\boldsymbol{t}_{\text {deceased, on } 1 \text { January } 2018}$
}

Correspondence: Rodrigo Gastón Gibilisco (gibilisco@uni-wuppertal.de) and Iustinian Gabriel Bejan (iustinian.bejan@uaic.ro)

Received: 24 September 2019 - Discussion started: 13 February 2020

Revised: 20 May 2020 - Accepted: 15 June 2020 - Published: 29 July 2020

\begin{abstract}
The kinetics of the gas phase reactions of hydroxyl radicals with two unsaturated ketoethers (UKEs) at $(298 \pm 3) \mathrm{K}$ and $1 \mathrm{~atm}$ of synthetic air have been studied for the first time using the relative-rate technique in an environmental reaction chamber by in situ Fourier-transform infrared spectroscopy (FTIR). The rate coefficients obtained using propene and isobutene as reference compounds were (in units of $10^{-10} \mathrm{~cm}^{3}$ molecule ${ }^{-1} \mathrm{~s}^{-1}$ ) as follows: $k_{\mathrm{TMBO}}$ $(\mathrm{OH}+(E)-4$-methoxy-3-buten-2-one $)=(1.41 \pm 0.11)$

and $k_{\mathrm{MMPO}}(\mathrm{OH}+(1 E)-1-m e t h o x y-2-m e t h y l-1-p e n t e n-$ 3 -one $)=(3.34 \pm 0.43)$. In addition, quantification of the main oxidation products in the presence of $\mathrm{NO}_{x}$ has been performed, and degradation mechanisms for these reactions were developed. Methyl formate, methyl glyoxal, peroxyacetyl nitrate (PAN) and peroxypropionyl nitrate (PPN) were identified as main reaction products and quantified for both reactions. The results of the present study provide new insights regarding the contribution of these multifunctional volatile organic compounds (VOCs) in the generation of secondary organic aerosols (SOAs) and long-lived nitrogen containing compounds in the atmosphere. Atmospheric lifetimes and implications are discussed in light of the obtained results.
\end{abstract}

\section{Introduction}

Oxygenated volatile organic compounds (OVOCs) are ubiquitous atmospheric constituents of anthropogenic and natural origin. From those OVOCs, carbonyls have both direct and indirect sources, as a result of biogenic and anthropogenic activities, and because they are formed during chemical degradation processes, which occur in the atmosphere. Unsaturated carbonyls present high reactivity and are easily decomposed throughout chemical reactions into various OVOCs products.

Ketones are one of the dominant groups of carbonyls found in the lower troposphere. They can be emitted into the atmosphere by anthropogenic activities from industry and combustion engine vehicle exhaust and in a large extent are formed as reaction products of other volatile organic compounds (VOCs) in the troposphere (Calvert et al., 2011; Jiménez et al., 2014; Mellouki et al., 2015).

More complex unsaturated carbonyls, namely the $\alpha, \beta$ unsaturated ketones and $\alpha, \beta$-unsaturated ethers are either emitted by plants or are produced as a result of atmospheric oxidation of conjugated dienes (Lv et al., 2018; Mellouki et al., 2015; Zhou et al., 2006). These compounds have been considered as precursors for secondary organic aerosols (SOAs) (Calvert et al., 2011). 
$\alpha, \beta$-unsaturated ketoethers are compounds with high structural complexity found in the atmosphere. They were detected as reaction products of the atmospheric degradation of furans and unsaturated ethers, compounds which received substantial interest in the last decade, since they are considered promising alternative fuels (Cilek et al., 2011; Li et al., 2018; Villanueva et al., 2009; Zhou et al., 2006). UKEs are also produced during combustion and more specifically in biomass burning (Hatch et al., 2015). They are also of great interest in the pharmaceutical industry, since they are often used as precursors and/or intermediates in the production of new anticancer drugs (Gøgsig et al., 2012; Kumar et al., 2016).

$\alpha, \beta$-unsaturated ketoethers are a special type of olefins, with an electron-rich $\pi$ system, which makes them more susceptible to rapid oxidation by addition of the $\mathrm{OH}$ radical to the double bond. Secondary pollutants, which are formed in such a reaction sequence, could be even more harmful than primary pollutants emitted into the atmosphere. Examples of such secondary harmful pollutants are organic peroxynitrates, highly oxidized molecules and SOAs (Atkinson, 2000; Calvert et al., 2015).

Accordingly, it is important to study in detail how the $\mathrm{OH}$ radical initiated oxidation of these compounds can affect the chemical composition and reactivity of the troposphere and, furthermore, the impact of the secondary pollutants formed during their gas phase chemical degradation.

In the present work the $\mathrm{OH}$ radical initiated reactions of (1E)-1-methoxy-2-methyl-1-penten-3-one and $(E)$ 4-methoxy-3-buten-2-one have been investigated.

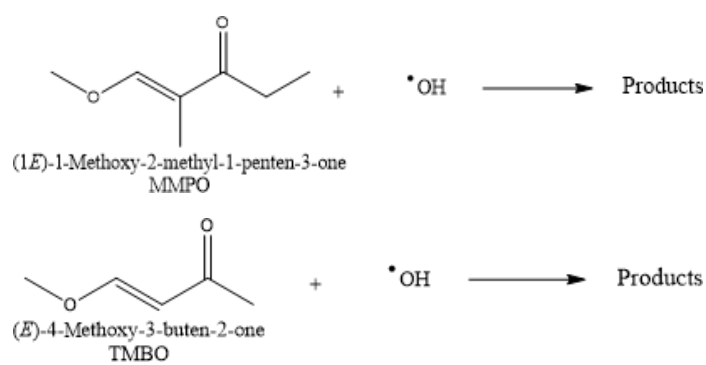

In addition to the kinetic information, the gaseous reaction products of Reactions (R1) and (R2) have been quantified, and reaction mechanisms have been derived for both compounds.

The present study represents the first experimental determination of the rate coefficients $\left(k_{\mathrm{TMBO}}\right.$ and $\left.k_{\mathrm{MMPO}}\right)$ and the reaction products formed from the gas phase reactions in the presence of $\mathrm{NO}_{x}$. The obtained results could be used to generate more complete atmospheric chemical degradation mechanisms, i.e. the master chemical mechanism, which is necessary for a better estimation of the contribution of such compounds to photooxidant and SOAs formation.

\section{Experimental}

All experiments were performed in a $1080 \mathrm{~L}$ quartz-glass reaction chamber at $(298 \pm 3) \mathrm{K}$ and a total pressure of $(760 \pm$ 10) Torr of synthetic air. A pumping system consisting of a turbo-molecular pump backed by a double-stage rotary fore pump was used to evacuate the reactor to $10^{-3}$ Torr. Three magnetically coupled Teflon mixing fans are mounted inside the chamber to ensure homogeneous mixing of the reactants. The photolysis system consists of 32 superactinic fluorescent lamps (Philips TL05 40W: 290-480 nm, $\lambda_{\max }=$ $360 \mathrm{~nm}$ ) and 32 low-pressure mercury vapour lamps (Philips TUV $40 \mathrm{~W} ; \lambda_{\max }=254 \mathrm{~nm}$ ), which are spaced evenly around the reaction vessel. The lamps are wired in parallel and can be switched individually, which allows for variation of the light intensity and thus also the photolysis frequency and radical production rate, within the chamber. The chamber is equipped with a White type multiple-reflection mirror system with a base length of $(5.91 \pm 0.01) \mathrm{m}$ for sensitive in situ long-path infrared absorption monitoring of reactants and products in the spectral range $4000-700 \mathrm{~cm}^{-1}$. The White system was operated at 82 traverses, giving a total optical path length of $(484.7 \pm 0.8) \mathrm{m}$. Infrared spectra were recorded with a spectral resolution of $1 \mathrm{~cm}^{-1}$ using a Nicolet Nexus FTIR (Fourier-transform infrared spectroscopy) spectrometer equipped with a liquid-nitrogen-cooled mercurycadmium-telluride (MCT) detector.

$\mathrm{OH}$ radicals were generated by photolysis of $\mathrm{CH}_{3} \mathrm{ONO} /$ air mixtures at $360 \mathrm{~nm}$ using fluorescent lamps.

$$
\begin{aligned}
& \mathrm{CH}_{3} \mathrm{ONO}+h v \rightarrow \mathrm{CH}_{3} \mathrm{O}+\mathrm{NO} \\
& \mathrm{CH}_{3} \mathrm{O}+\mathrm{O}_{2} \rightarrow \mathrm{CH}_{2} \mathrm{O}+\mathrm{HO}_{2} \\
& \mathrm{HO}_{2}+\mathrm{NO} \rightarrow \mathrm{OH}+\mathrm{NO}_{2}
\end{aligned}
$$

Quantification of TMBO and MMPO and gas phase products was performed by comparison with calibrated reference spectra contained in the infrared (IR) spectral databases of the Wuppertal laboratory.

To investigate the mechanism of the $\mathrm{OH}$-radical-initiated oxidation of the $\alpha, \beta$-unsaturated ketoethers, the mixtures of the compound, $\mathrm{CH}_{3} \mathrm{ONO}$ and air were irradiated for periods of 10-30 min during which infrared spectra were recorded with the FTIR spectrometer. Typically, up to 128 interferograms were co-added per spectrum over a period of approximately $40 \mathrm{~s}$, and $15-20$ of such spectra were collected. Prior to the reaction initiated by $\mathrm{OH}$ radicals, five spectra had been collected in the dark to check the homogeneity and unexpected dark decay of the compounds under investigation (e.g. wall losses and dark reactions).

The TMBO, MMPO and reference compounds were monitored at the following infrared absorption frequencies (in $\mathrm{cm}^{-1}$ ): TMBO at 958,1253 and 3020; MMPO at 1245, 1653 and 2850; isobutene at 3085; and propene at 3091.

Rate coefficients for the reactions of $\mathrm{OH}$ radicals with MMPO and TMBO were determined by comparing their de- 
cay rate with that of the corresponding decay of the two reference compounds, isobutene and propene.

$\mathrm{OH}+\mathrm{UKE} \rightarrow$ Products

$\mathrm{OH}+$ Reference $\rightarrow$ Products.

Provided that the reference compound and TMBO and MMPO are lost only by Reactions (R6) and (R7), it can be shown that

$\ln \left\{\frac{[\mathrm{UKE}] 0}{[\mathrm{UKE}] t}\right\}=\frac{k_{\mathrm{UKE}}}{k_{\text {reference }}} \ln \left\{\frac{[\text { reference }] 0}{\text { [reference }]}\right\}$,

where $[\mathrm{UKE}]_{0},[\text { reference }]_{0},[\mathrm{UKE}]_{t}$ and $[\text { reference }]_{t}$ are the concentrations of the $\alpha, \beta$-unsaturated ketoethers and the reference compound at times $t=0$ and $t$, respectively, and $k_{\mathrm{UKE}}$ and $k_{\text {reference }}$ are the rate coefficients of Reactions (R6) and (R7), respectively.

The initial mixing ratios of the reactants in ppmv $\left(1 \mathrm{ppmv}=2.46 \times 10^{13}\right.$ molecule $\mathrm{cm}^{-3}$ at $298 \mathrm{~K}$ and $\left.1 \mathrm{~atm}\right)$ were TMBO (1-3), MMPO (2-4), isobutene (3-5) and propene (3-5). Methyl nitrite (6 ppmv) photolysis has been used for $\mathrm{OH}$ radical formation. No additional $\mathrm{NO}$ has been introduced in the reaction chamber.

Possible additional losses due to interferences and/or interactions with the reactor walls could be neglected or corrected. To verify this assumption, mixtures of $\mathrm{CH}_{3} \mathrm{ONO} /$ air with the $\alpha, \beta$-unsaturated ketoethers and the reference compound were prepared and allowed to stand in the dark for $2 \mathrm{~h}$. In all cases, the decay of the organic species in the presence of the $\mathrm{OH}$ radical precursor and in the absence of ultraviolet (UV) light was negligible. Furthermore, to test for a possible photolysis of the compounds, the reactant mixtures without $\mathrm{OH}$ radical precursor were irradiated for $30 \mathrm{~min}$, using all lamps surrounding the chamber. No significant photolysis of any of the reactants was observed, and no additional decay has been monitored due to a possible reaction with interfering radicals.

\section{Materials}

The following chemicals, with purities as stated by the supplier, were used without further purification: synthetic air (Air Liquide, 99.999\%), propene (Messer Schweiz AG, $99.5 \%$ ), isobutene (Messer, $99 \%),(E)$-4-methoxy-3-buten2-one technical grade (Aldrich, $90 \%$ ) and (1E)-1-methoxy2-methyl-1-penten-3-one (Aldrich, >89.5\%). Methyl nitrite was prepared by the dropwise addition of $50 \%$ sulfuric acid to a saturated solution of sodium nitrite in water and methanol (Taylor et al., 1980). The products were carried by a stream of nitrogen gas through a saturated solution of sodium hydroxide followed by calcium chloride to remove the excess of acid, water and methanol, respectively. Methyl nitrite was collected and stored at $193 \mathrm{~K}$ in dry ice.

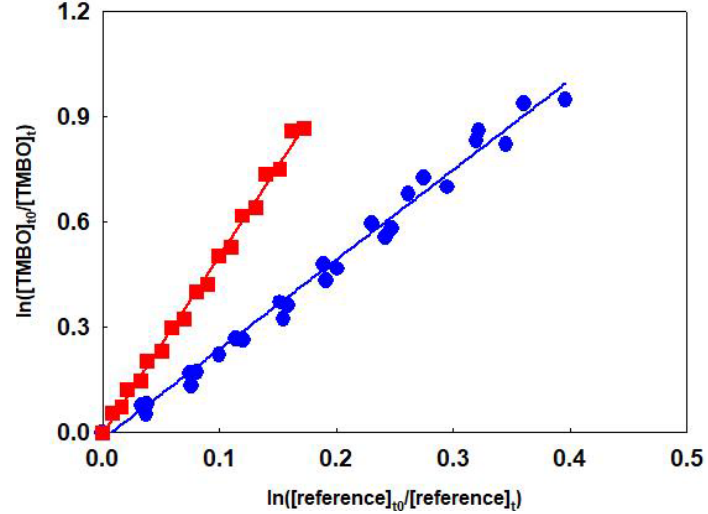

Figure 1. Relative-rate data for the reaction of $\mathrm{OH}$ radicals with $(E)$-4-methoxy-3-buten-2-one using propene $(\square)$ and isobutene $(\bullet)$ as reference compounds at $298 \mathrm{~K}$ and the atmospheric pressure of air.

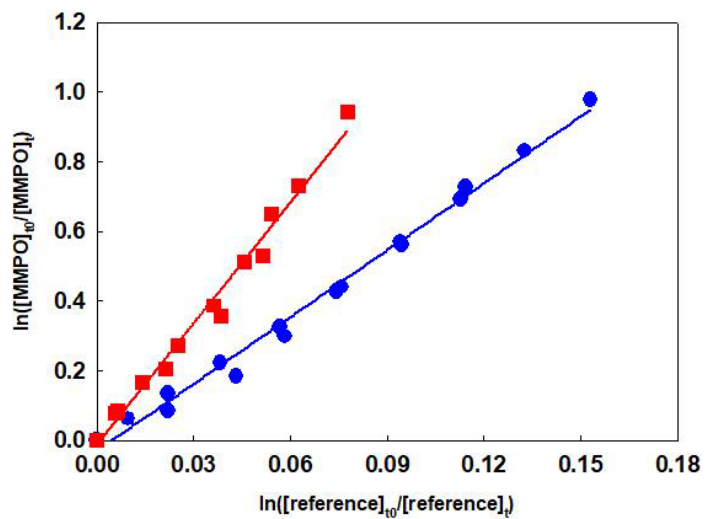

Figure 2. Relative-rate data for the reaction of $\mathrm{OH}$ radicals with (1E)-1-methoxy-2-methyl-1-penten-3-one using propene $(\square)$ and isobutene (๑) as reference compounds at $298 \mathrm{~K}$ and the atmospheric pressure of air.

\section{Results and discussion}

\subsection{Rate coefficients for the reaction with $\mathrm{OH}$ radicals}

Plots of the kinetic data obtained from the experiments of the reaction of $\mathrm{OH}$ radicals with TMBO and MMPO using two different reference compounds are shown in Figs. 1 and 2, respectively. At least two experiments have been performed for each reference compound, and linear plots were obtained in all cases. For better representation, data for all experiments have been plotted against both references. The rate coefficient ratio of $k_{\mathrm{UKE}} / k_{\text {reference }}$ $( \pm 2 \sigma)$ obtained by combining the experiments results in Figs. 1 and 2 were for TMBO, $k_{\mathrm{TMBO}} / k_{\text {isobutene }}=(2.56 \pm$ $0.13)$ and $\quad k_{\mathrm{TMBO}} / k_{\text {propene }}=(5.08 \pm 0.16) \quad$ and for $\mathrm{MMPO}, \quad k_{\mathrm{MMPO}} / k_{\text {isobutene }}=(6.40 \pm 0.31) \quad$ and $k_{\mathrm{MMPO}} / k_{\text {propene }}=(11.64 \pm 0.82)$. 
The linearity of the plots with near-zero intercepts confirms that no interferences have affected the rate coefficient determination. Additionally, the very good agreement of the rate coefficients using the two reference compounds proved the correctness of the investigations.

Table 1 lists the values of the rate coefficient ratio of $k_{\mathrm{UKE}} / k_{\text {reference }}$ obtained in the individual experiments at $298 \mathrm{~K}$ and 1 atm for each $\alpha, \beta$-unsaturated ketoether. The errors given for the $k_{\mathrm{UKE}} / k_{\text {reference }}$ ratios are the $2 \sigma$ statistical errors from the linear regression. The rate coefficients $k_{\mathrm{UKE}}$ for Reactions $\mathrm{R} 1$ and R2 were calculated using the recommended values $k_{\text {propene }}=(2.90 \pm 0.10) \times 10^{-11} \mathrm{~cm}^{3}$ molecule $\mathrm{e}^{-1} \mathrm{~s}^{-1}$ (Atkinson et al., 2006) $(\mathrm{OH}+$ propene $)$ and $k_{\text {isobutene }}=(5.23 \pm$ $0.24) \times 10^{-11} \mathrm{~cm}^{3}$ molecule ${ }^{-1} \mathrm{~s}^{-1}(\mathrm{OH}+$ isobutene) (Atkinson and Aschmann, 1984).

In addition, Table 1 shows the rate coefficients for individual experiments of each reference compound employed in this study as well as the final quoted rate coefficients for the reactions of $\mathrm{OH}$ with UKE compounds as an average from all experimental values obtained for the corresponding compound. The error quoted for those final UKE rate coefficients is obtained by using an error propagation approach.

To the best of our knowledge rate coefficients for the reactions of $\mathrm{OH}$ radicals with $(E)$-4-methoxy-3-buten-2-one and (1E)-1-methoxy-2-methyl-1-penten-3-one have not been reported previously in the literature.

\subsubsection{Reactivity trends}

There is a general lack of studies on the reactivity of polysubstituted oxygenated unsaturated compounds, such as the unsaturated ketoethers studied in this work.

Only the reactivity of $(E)$-4-methoxy-3-buten-2-one towards ozone was investigated by Grosjean and Grosjean (1999), who reported a rate coefficient $k_{\mathrm{O}_{3}}$ of $1.3 \times$ $10^{-16} \mathrm{~cm}^{3}$ molecule $\mathrm{s}^{-1} \mathrm{~s}^{-1}$ (Grosjean and Grosjean, 1999). The authors identified and quantified two main products from the ozonolysis of $(E)$-4-methoxy-3-buten-2-one, namely methyl glyoxal $(31.2 \pm 1.9 \%)$ and methyl formate $(>15.7 \%)$. These two species are potential products of the OH-initiated oxidation of (E)-4-methoxy-3-buten-2-one as well.

It is well known that $\mathrm{OH}$-initiated atmospheric degradation of unsaturated VOCs proceeds mainly through the addition of the $\mathrm{OH}$ radical to the double bond (Calvert et al., 2015). Some studies also suggested that the presence of oxygenated functional groups in unsaturated VOCs leads to an increase of $k_{\mathrm{OH}}$, perhaps due to the possibility of hydrogen-bonding transition complexes stabilizing the transition states involved in these reactions (Blanco et al., 2012; Gaona-Colmán et al., 2017; Mellouki et al., 2003).

Considering the findings mentioned above, it is interesting to analyse the possible effect on $k_{\mathrm{OH}}$ when the ether group (R-O) is directly attached to the $\mathrm{C}=\mathrm{C}$ bond of the unsatu- rated ketones and the presence of different substituents in the molecule. For this purpose, Table 2 presents two basic structures of unsaturated ketones (I and II) and the $\mathrm{OH}$ rate coefficients for different unsaturated ketones obtained experimentally and/or estimated using a structure-activity relationship (SAR) method (US EPA, 2018).

Starting with the less substituted compound, when the substituents $R_{1}, R_{2}$ and $R_{3}$ are all hydrogen atoms (3-buten-2one), a value of $k_{\mathrm{OH}}=2 \times 10^{-11} \mathrm{~cm}^{3}$ molecule ${ }^{-1} \mathrm{~s}^{-1}$ was experimentally observed (Holloway et al., 2005). Successive replacement of $\mathrm{H}$ atoms with methyl groups, for the positions $R_{2}$ (3-penten-2-one) and $R_{3}$ (4-methyl-3-penten-2one), leads to a considerable increment on the reactivity as shown in Table 2 (Blanco et al., 2012; Gaona-Colmán et al., 2017). Considering the experimental errors of the measurements, it is reasonable to conclude that the addition of each methyl group leads to an increase of approximately $4 \times 10^{-11} \mathrm{~cm}^{3}$ molecule $\mathrm{s}^{-1} \mathrm{~s}^{-1}$ in the rate coefficient relative to those of basic structure (I).

The methyl group added in positions $R_{2}$ and $R_{3}$ would stabilize the radical formed after the addition of the $\mathrm{OH}$ at the $\mathrm{C}_{\alpha}$ for two different effects: (i) the positive inductive effect $(\mathrm{I}+)$ by the methyl group, which stabilizes the positive charge in the $\mathrm{C}_{\beta}$ atom, and (ii) the stabilization due to the hyperconjugation of the carbocation formed at $\mathrm{C}_{\beta}$.

Comparing the experimental value $k_{\mathrm{TMBO}}=1.41 \times$ $10^{-10} \mathrm{~cm}^{3}$ molecule ${ }^{-1} \mathrm{~s}^{-1}$ obtained in the present work for (E)-4-methoxy-3-buten-2-one with its methylated analogue 3 -penten-2-one, one can easily realize the increase by a factor of 2 in the rate coefficient when the $R_{3}$ substituent is a methoxy group. This can be explained by the oxygen's lone pair of electrons, which delocalizes and increases the electron density within the $\mathrm{C}=\mathrm{C}$ bond. On the other hand, the methoxy group is electron withdrawing through a negative inductive effect (I-) via the $\sigma$ bonds. However, the mesomeric effect is stronger than the inductive one, which is reflected by an increase of the $(E)$-4-methoxy-3-buten-2one $+\mathrm{OH}$ reaction rate coefficient compared to its mono- and bi-methylated analogues that can stabilize the corresponding radical structures only by the inductive effect and hyperconjugation but not by a mesomeric effect.

A similar assessment can be performed considering the basic structure (II). The increasing trend in the reactivity towards $\mathrm{OH}$ radicals is quite similar when methyl groups replace $\mathrm{H}$ atoms in the structure of 1-pentene3 -one. The experimental rate coefficient $k_{\mathrm{MMPO}}=3.34 \times$ $10^{-10} \mathrm{~cm}^{3}$ molecule ${ }^{-1} \mathrm{~s}^{-1}$ obtained in the present work for the reaction of $\mathrm{OH}$ radicals with (1E)-1-methoxy-2-methyl1-penten-3-one is quite high, but considering the approximate individual contribution of the substituents on the $\mathrm{C}=\mathrm{C}$ bond as was assumed previously for the basic structure (I) reflects entirely the system reactivity. 
Table 1. Rate coefficient ratio of $k_{\mathrm{UKE}} / k_{\text {reference }}$ and rate coefficients for the reaction of $\mathrm{OH}$ radicals with $(E)$-4-methoxy-3-buten-2-one and (1E)-1-methoxy-2-methyl-1-penten-3-one at (298 \pm 3$) \mathrm{K}$ in $1 \mathrm{~atm}$ of air.

\begin{tabular}{|c|c|c|c|}
\hline Compound & Reference & $k_{\mathrm{UKE}} / k_{\text {reference }}$ & $\left(10^{-10} \mathrm{~cm}^{3}\right.$ molecule $\left.{ }^{-1} \mathrm{~s}^{-1}\right)$ \\
\hline \multirow{6}{*}{$\begin{array}{l}\text { (E)-4-Methoxy- } \\
\text { 3-buten-2-one }\end{array}$} & Isobutene & $2.41 \pm 0.02$ & $1.26 \pm 0.06$ \\
\hline & Isobutene & $2.74 \pm 0.04$ & $1.43 \pm 0.07$ \\
\hline & Isobutene & $2.67 \pm 0.09$ & $1.40 \pm 0.10$ \\
\hline & Propene & $5.02 \pm 0.06$ & $1.46 \pm 0.05$ \\
\hline & Propene & $5.20 \pm 0.07$ & $1.51 \pm 0.06$ \\
\hline & Average & & $1.41 \pm 0.11$ \\
\hline \multirow{5}{*}{$\begin{array}{l}\text { (1E)-1-Methoxy- } \\
\text { 2-methyl-1-penten-3-one }\end{array}$} & Isobutene & $6.30 \pm 0.12$ & $3.30 \pm 0.16$ \\
\hline & Isobutene & $6.54 \pm 0.38$ & $3.42 \pm 0.25$ \\
\hline & Propene & $11.00 \pm 0.77$ & $3.19 \pm 0.25$ \\
\hline & Propene & $11.88 \pm 0.49$ & $3.45 \pm 0.19$ \\
\hline & Average & & $3.34 \pm 0.43$ \\
\hline
\end{tabular}

\subsubsection{Structure-activity relationship (SAR) calculations}

In the present work, the AOPWIN (Atmospheric Oxidation Program) software included in the EPI Suite 4.1 (Estimation Programs Interface) was used to estimate the rate coefficients of the structures listed in Table 2 (US EPA. Estimation Programs Interface Suite ${ }^{\mathrm{TM}}$ for Microsoft ${ }^{\circledR}$ Windows, 2018).

It is worth mentioning that calculated $k_{\mathrm{OH}}$ with AOPWIN fit quite well with the experimental values of the simplest structures of the unsaturated ketones shown in Table 2, namely 3-buten-2-one and 1-penten-3-one. However, when the hydrogen atoms are replaced by methyl groups in the $\mathrm{C}=\mathrm{C}$ system for structures (I) and (II), differences between experimental values and those estimated using the SAR method become evident by a factor of 1.2 and 1.5 , respectively. For structure (I) with two methyl substituents (4-methyl-3-penten-2-one) the difference remains approximately the same (factor of 1.3).

Comparing the kinetic results obtained in this work for MMPO and TMBO with those predicted by AOPWIN, the differences become substantially larger. In Table 2 it can be seen that for $k_{\mathrm{TMBO}}$ the results differ by a factor of 2 and for $k_{\text {MMPO }}$ by a factor of 3 .

This fact highlights the limitations of the AOPWIN-SAR method for predicting the specific site for the addition of the $\mathrm{OH}$ radical to each carbon atom of an asymmetrical alkene, ignoring a possible stabilization of the reaction intermediate. The stabilization could generate transition states involving the formation of hydrogen-bonding complexes between the $\mathrm{OH}$ radical and the oxygenated substituents as was suggested in previous publications (Blanco et al., 2012; Gaona-Colmán et al., 2017; Mellouki et al., 2003).

In conclusion, the AOPWIN-SAR estimation of reaction rate coefficients is a useful tool for simple molecules. However, the $\mathrm{OH}$ rate coefficients of the unsaturated ketoethers reported in this work showed significant discrepancies compared with the predicted ones. Probably, as suggested recently by Vereecken et al. (2018), it is not clear if the SAR method can be easily expanded to multifunctional compounds, especially given the small training set available from which to derive cross-substituent parameters or base rate coefficients (Vereecken et al., 2018).

\subsection{Reaction product distribution and mechanism}

\subsection{1 (E)-4-methoxy-3-buten-2-one $+\mathrm{OH}$ radicals}

Figure 3 shows an IR spectrum recorded before (trace A) UV irradiation applied for a mixture of TMBO and $\mathrm{CH}_{3} \mathrm{ONO}$ in air. Trace B shows the spectrum recorded after 10 min of UV irradiation of the reaction mixture. Trace $\mathrm{D}$ exhibits the product spectrum after subtraction of non-reacted TMBO (from the reference spectra of trace $\mathrm{C}$ ), $\mathrm{NO}, \mathrm{NO}_{2}, \mathrm{CH}_{3} \mathrm{ONO}$ and $\mathrm{H}_{2} \mathrm{O}$. Traces E, F and $\mathrm{G}$ show reference spectra of methyl formate, peroxyacetyl nitrate (PAN) and methyl glyoxal, respectively. Trace $\mathrm{H}$ exhibits the residual product spectrum that is obtained after subtraction of known products from the product spectrum in trace $\mathrm{D}$. The absorption from $\mathrm{CO}_{2}$ has been removed in all traces for clarity, since the band was saturated and no information could be obtained from it accordingly. Methyl formate, peroxyacetyl nitrate, and methyl glyoxal were readily identifiable as reaction products. Concentration-time profiles of TMBO and the identified products, methyl formate, PAN and methyl glyoxal are shown in Fig. 4. The concentration-time distribution supports that methyl formate, methyl glyoxal and PAN are primary reaction products. It is also easy to observe the constant concentrations of TMBO prior to reaction begin. This is accountable for homogeneity of the reaction mixture. Five spectra have been collected before switching on the light which corresponds to $240 \mathrm{~s}$. No decay of TMBO is present in this time suggesting missing dark interference in the reaction 


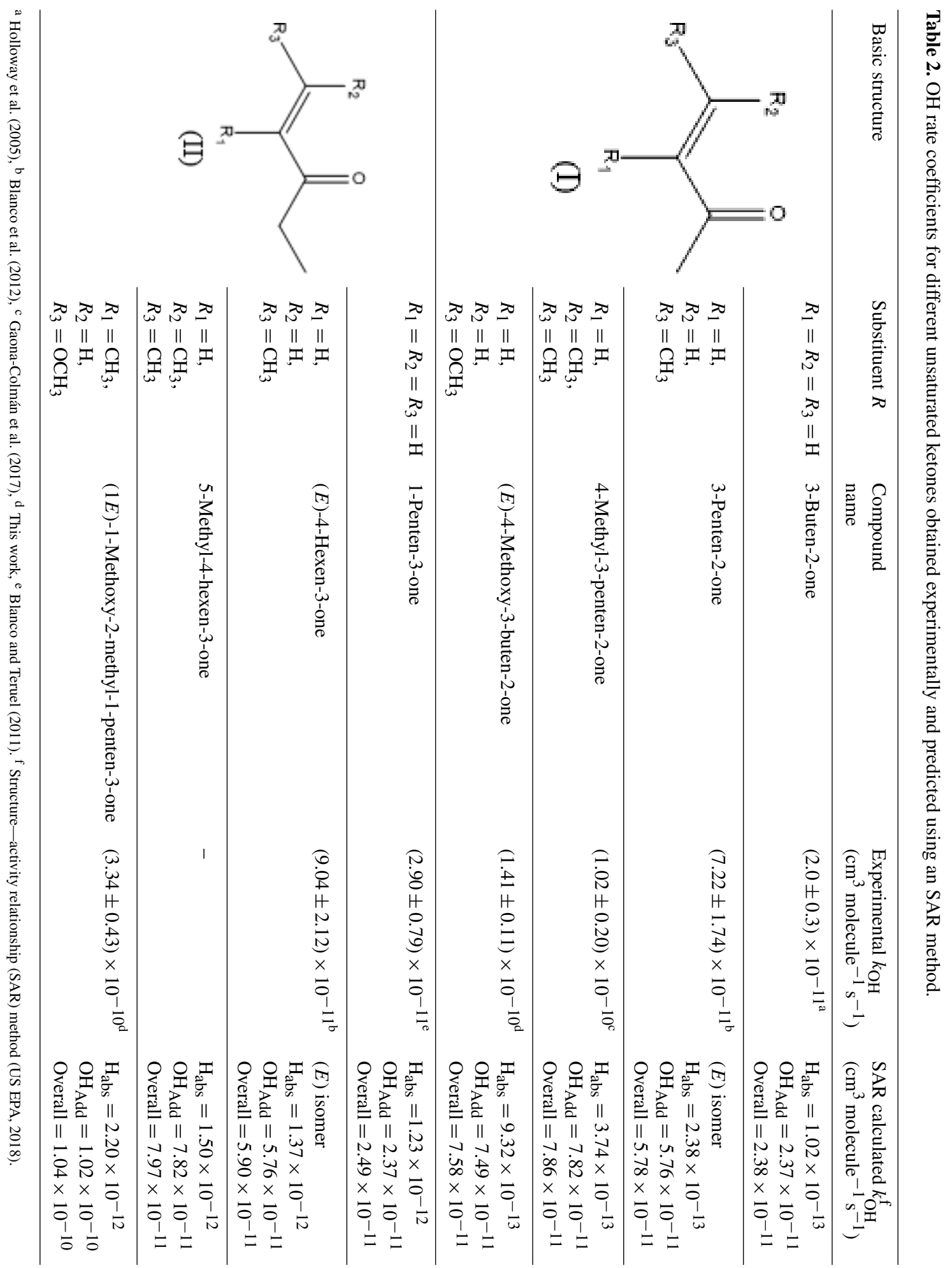




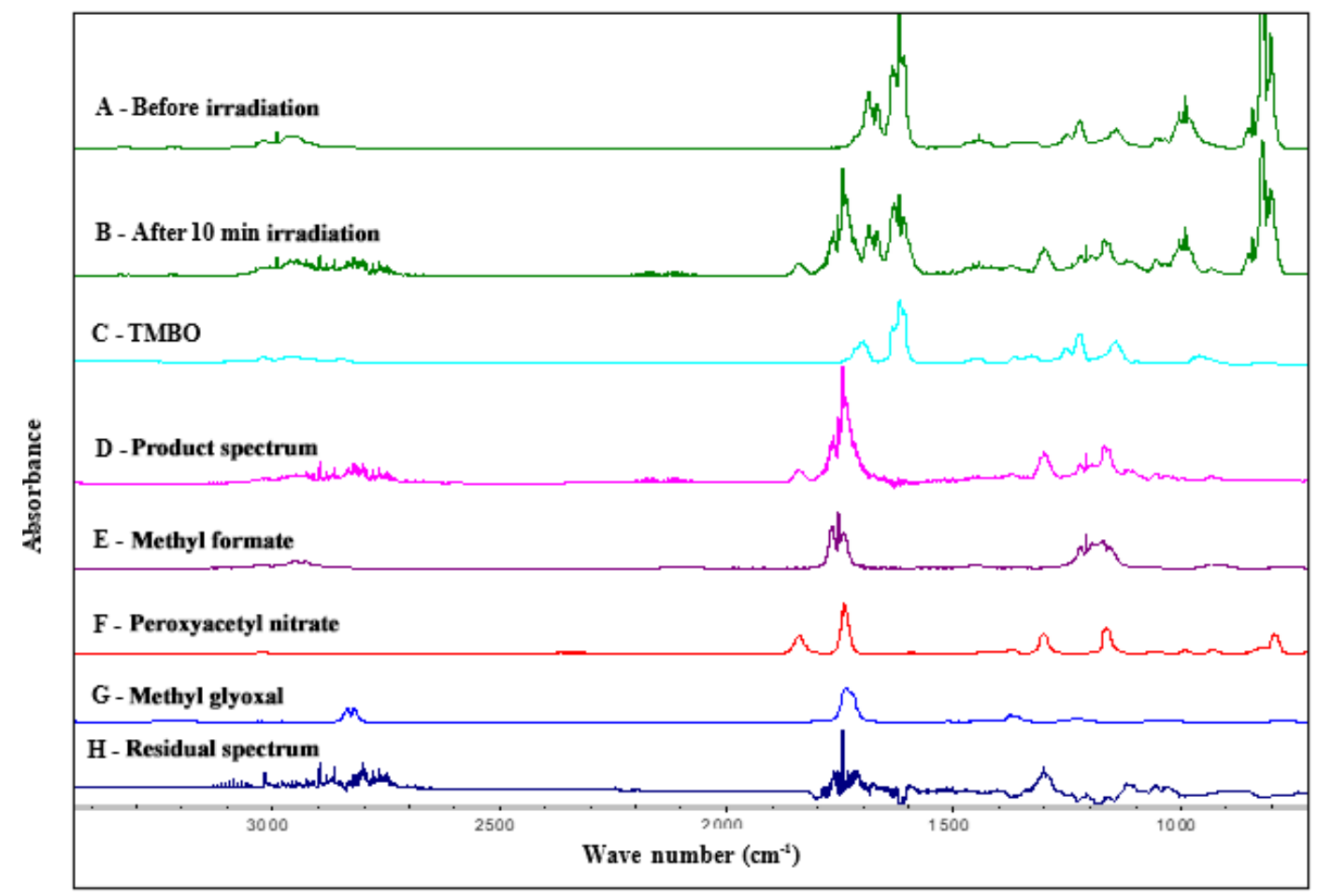

Figure 3. Infrared spectral data. Trace A: infrared spectrum of a $\mathrm{TMBO} / \mathrm{CH}_{3} \mathrm{ONO} /$ air reaction mixture before irradiation. Trace B: mixture after 10 min irradiation. Trace C: reference spectrum of TMBO. Trace D: product spectrum. Trace E: reference spectrum of methyl formate. Trace F: reference spectrum of peroxyacetyl nitrate. Trace G: reference spectrum of methyl glyoxal. Trace H: residual spectrum after subtraction of the identified reaction products in trace D.

system. From Fig. 4 a conversion of up to $80 \%$ of TMBO in $10 \mathrm{~min}$ of reaction time could be observed.

Depending on the side addition of the $\mathrm{OH}$ radical leading to the $\mathrm{C}_{\alpha}$ or $\mathrm{C}_{\beta}$, hydroxyalkoxy radicals, $A_{1}$ and $B_{1}$ will be formed, respectively (Scheme 1). Decomposition of the $A_{1}$ radical will lead to the formation of methyl formate and methyl glyoxal as primary products. On the other hand, the $\mathrm{C}_{3}-\mathrm{C}_{4}$ bond scission in the $B_{1}$ radical will lead to the formation of methyl formate and methyl glyoxal. Additionally, the radical $B_{1}$ could decompose through a $C_{2}-C_{3}$ scission generating 2-hydroxy-2-methoxyacetaldehyde and the acetyl radical. This route would, beside the formation of 2-hydroxy2-methoxyacetaldehyde, be responsible for the primary generation of PAN through the further reaction of the acetyl radical with $\mathrm{O}_{2} / \mathrm{NO}_{2}$. In addition, PAN is known to be formed due to the oxidation of methyl glyoxal (Fischer et al., 2014). The reaction of $\mathrm{OH}$ radicals with methyl glyoxal occurs exclusively by abstraction of the aldehydic $\mathrm{H}$ atom to form $\mathrm{CH}_{3} \mathrm{C}(\mathrm{O}) \mathrm{CO}$ radicals, which have a very short lifetime, dissociating to form $\mathrm{CH}_{3} \mathrm{CO}+\mathrm{CO}$ (Green et al., 1990). Finally, it is expected that acetyl radicals react, in the presence of $\mathrm{O}_{2}$, with $\mathrm{NO}_{2}$ to form PAN (Fischer et al., 2014). Acetyl radicals are of particular importance in atmospheric chemistry, as they are key contributors to important pollutants in the atmosphere. PAN (peroxyacetyl nitrate), in high $\mathrm{NO}_{x}$ envi- ronments, is formed exclusively from acetyl peroxy radicals. However, in low $\mathrm{NO}_{x}$ environments, acetyl radicals, in the presence of oxygen, generate acetyl peroxy radicals, which further react with $\mathrm{HO}_{2}$ radicals producing $\mathrm{CH}_{3} \mathrm{C}(\mathrm{O}) \mathrm{OOH}$, $\mathrm{CH}_{3} \mathrm{C}(\mathrm{O}) \mathrm{OH}, \mathrm{O}_{3}$ and $\mathrm{OH}$ radicals. These secondary products could have a high impact on the atmospheric chemistry on the global scale (Winiberg et al., 2016).

After subtraction of the identified products, the most prominent absorption feature in the IR residual spectra (Fig. 3, trace H) is a carbonyl band at $1730 \mathrm{~cm}^{-1}$, which is more characteristic for an aldehydic than a ketone absorption. This feature suggests the formation of 2-hydroxy-2methoxyacetaldehyde, which is unfortunately not commercially available. Therefore, direct identification in the residual product spectrum is not possible by using a recorded IR reference spectrum.

Carbonyl absorptions in the IR spectra are present in the $1600-1800 \mathrm{~cm}^{-1}$ range and 2-hydroxy-2methoxyacetaldehyde identification in this region of the IR spectrum is not possible. Beside the parent compound, which is presenting features in this carbonyl absorption specific region, many other products formed during the reaction have absorptions in this range. All the products formed in the reaction system have a specific absorption in the carbonyl range (methyl glyoxal, methyl formate, 


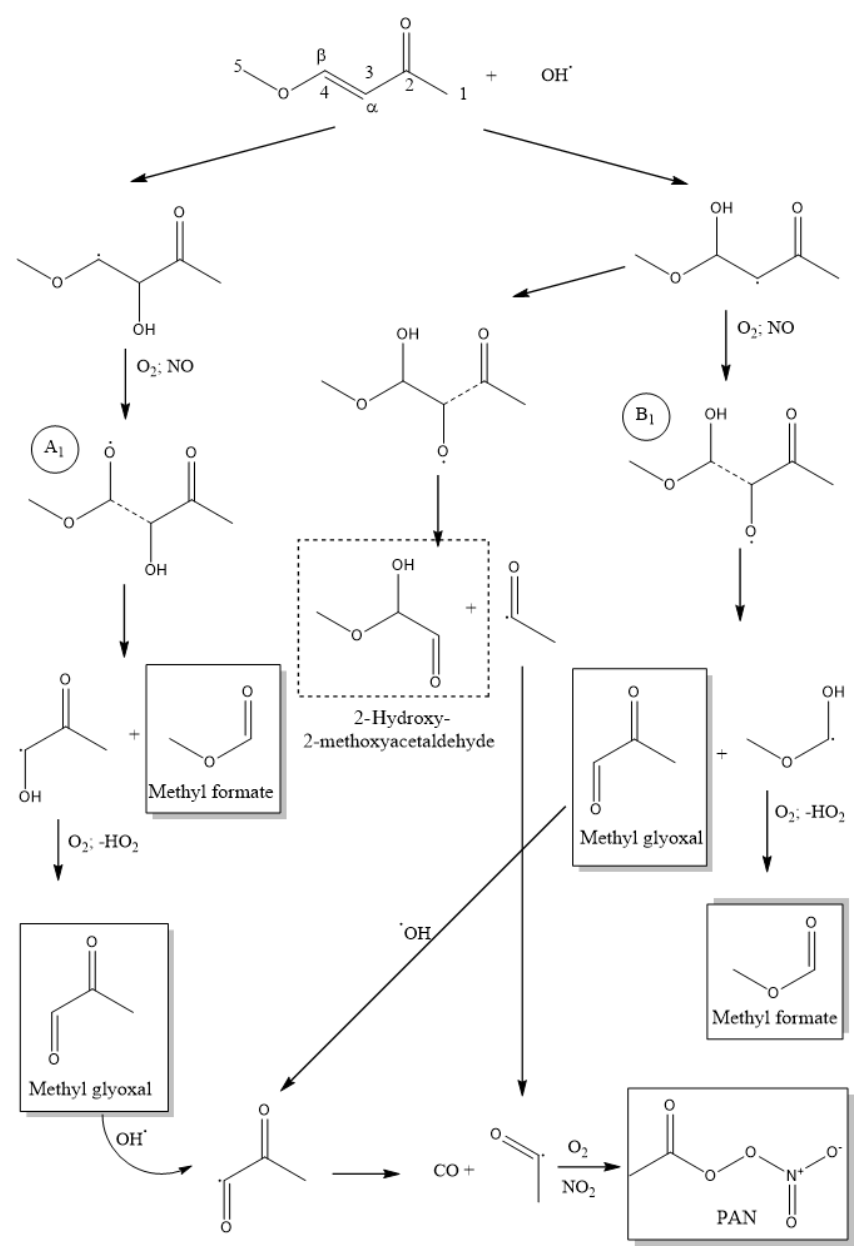

Scheme 1. Simplified reaction mechanism for the addition channel in the OH-radical-initiated oxidation of $(E)$-4-methoxy-3-buten-2one. Quantified products appear in the boxes, and the identified products are rounded by a dashed rectangle.

PAN and 2-hydroxy-2-methoxyacetaldehyde). However, the later one must have an important pronounced peak in the $\mathrm{O}-\mathrm{H}$ absorption area; therefore, we may assume the unique absorption at $3550 \mathrm{~cm}^{-1}$ as being attributed to the O-H absorption of 2-hydroxy-2-methoxyacetaldehyde (Fig. S1 in the Supplement). This is a strong indication of the 2-hydroxy-2-methoxyacetaldehyde formation, which is in agreement with the proposed mechanism in Scheme 1.

Plots of the concentrations of the carbonyls formed vs. reacted TMBO give molar formation yields of $(65 \pm 12) \%$ for methyl formate, $(56 \pm 16) \%$ for PAN and $(69 \pm 14) \%$ for methyl glyoxal. The yields have been corrected for secondary reactions with $\mathrm{OH}$ radicals as well as for the photolysis and wall deposition processes where necessary (Tuazon et al., 1986). Exemplary plots for the product formation yields are shown in Fig. S2.

\subsection{2 (1E)-1-methoxy-2-methyl-1-penten-3-one + OH radicals}

Trace A in Fig. 5 shows the infrared spectrum for an initial reaction mixture of an $\mathrm{MMPO} / \mathrm{CH}_{3} \mathrm{ONO} /$ air mixture prior to irradiation; trace $\mathrm{B}$ exhibits the spectrum recorded after $10 \mathrm{~min}$ of irradiation and hence the occurring reaction; trace $\mathrm{C}$ shows a reference spectrum of MMPO recorded in a separate experiment in air at $1 \mathrm{~atm}$ and $298 \mathrm{~K}$; trace D shows the product spectrum recorded after $10 \mathrm{~min}$ of irradiation and after subtraction of non-reacted MMPO as well as subtraction of $\mathrm{CH}_{3} \mathrm{ONO}, \mathrm{NO}, \mathrm{H}_{2} \mathrm{O}$ and $\mathrm{NO}_{2}$ absorption bands; trace $\mathrm{E}$ shows a reference spectrum of methyl formate; trace $\mathrm{F}$ shows a reference spectrum of 2,3-pentanedione; and trace $\mathrm{G}$ shows a reference spectrum of peroxypropionyl nitrate (PPN). Trace $\mathrm{H}$ shows the residual product spectrum after subtraction of the identified reaction products in trace $\mathrm{D}$.

The absorption from $\mathrm{CO}_{2}$ has been removed in all traces for clarity, since the band was saturated and no additional information could be obtained, accordingly. Methyl formate and peroxypropionyl nitrate were identified as reaction products. Concentration-time profiles of MMPO, methyl formate and peroxypropionyl nitrate are shown in Fig. 6. Figure 6 supports that methyl formate and peroxypropionyl nitrate are primary reaction products. MMPO concentration is constant during five spectra recorded in the dark, which consist of $120 \mathrm{~s}$ mixing time. Perfect homogeneity and no dark interferences could be observed. From Fig. 6 a total conversion of MMPO in 10 min of reaction time could be observed.

After the addition of the $\mathrm{OH}$ radical to the double bond of MMPO and subsequent addition of an oxygen molecule followed by reaction with $\mathrm{NO}$, two different hydroxyalkoxy radicals, $A_{2}$ and $B_{2}$ (Scheme 2), could be generated. Unlike for TMBO, the reaction of MMPO with $\mathrm{OH}$ radicals at the $\mathrm{C}_{\beta}$ position could lead to the formation of the more stable tertiary radical $A_{2}$ due to the presence of a methyl group in the $\alpha$ position to the carbonyl group.

Scheme 2 shows that both addition channels would lead to the formation of methyl formate and 2,3-pentanedione if the hydroxyalkoxy radical would follow the dissociation of bond I in the $A_{2}$ radical intermediate and the dissociation of bond II in the $B_{2}$ radical intermediate.

The hydroxyalkoxy radical $B_{2}$ could lead, beside the formation of 2,3-pentanedione and methyl formate by following the scission of bond II, to the formation of 2-hydroxy2-methyl-3-oxopentanal as a product and formaldehyde as a reaction co-product as a result of the decomposition of the B2 radical from the scission of bond I. Formaldehyde could not be identified as a reaction product, since it is formed from $\mathrm{CH}_{3} \mathrm{ONO}$ photolysis and is present in the reaction spectra. 2Hydroxy-2-methyl-3-oxopentanal is not commercially available, and in the absence of a mass spectrometry technique, which could at least identify the mass of this product there, its formation is only an assumption. 


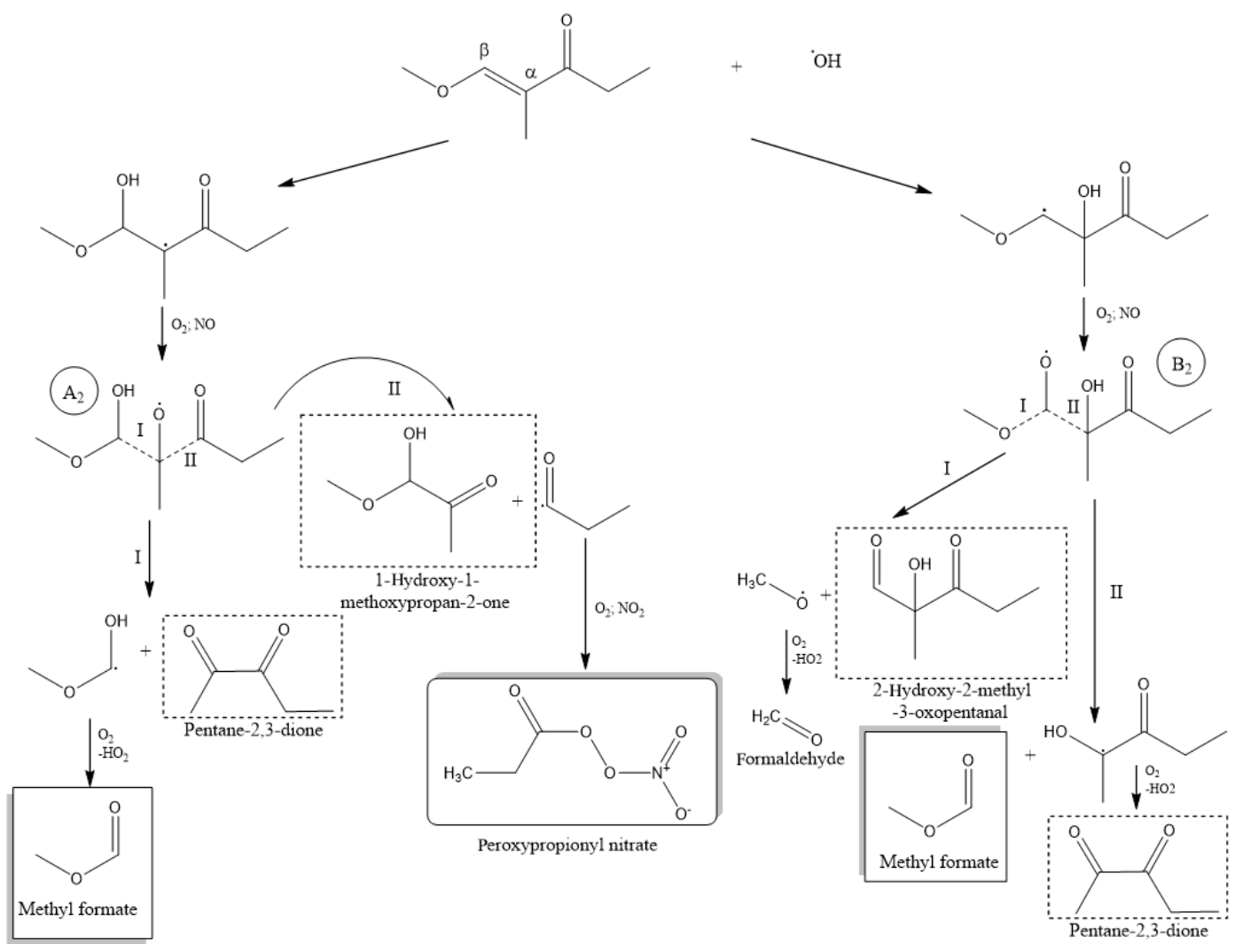

Scheme 2. Simplified reaction mechanism for the addition channel in the OH-radical-initiated oxidation of (1E)-1-methoxy-2-methyl-1penten-3-one. Quantified products appear in the boxes, and the identified products are rounded by a dashed rectangle.

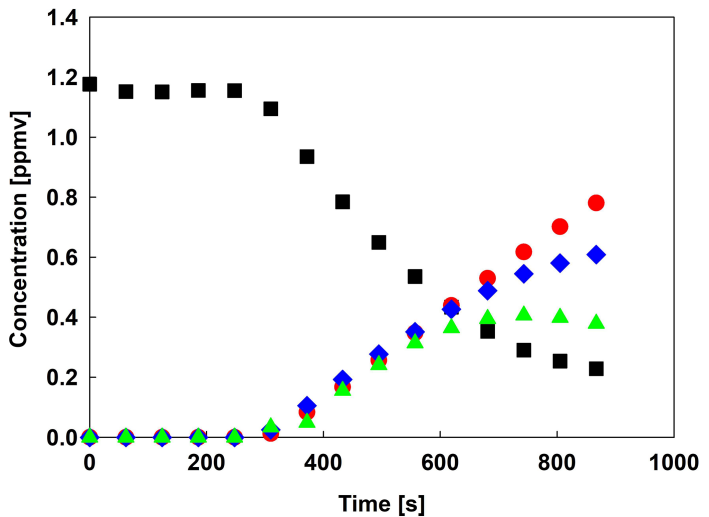

Figure 4. Concentration-time dependencies for the reaction of $\mathrm{TMBO}(\mathbf{\square})+\mathrm{OH}$ radicals and the quantified products, methyl formate $(\diamond \mathrm{MF})$, peroxyacetyl nitrate (OPAN) and methyl glyoxal $(\triangle \mathrm{MG})$.

Decomposition channel for the A2 radical could follow route I, leading to the formation of 2,3-pentanedione and the radical $\mathrm{CH}_{3} \mathrm{OCHOH}$, which could further, in the presence of oxygen, form methyl formate as a co-product. Trace $\mathrm{E}$ in Fig. 5 shows a reference spectrum of methyl formate. The ab- sorption bands at 1210 and $1755 \mathrm{~cm}^{-1}$ were used to identify and quantify the formation of methyl formate.

The formation of 2,3-pentanedione is confirmed qualitatively by comparison of the product spectrum (Fig. 5, trace D) with the existing reference spectrum (Fig. 5, trace F). Although there is no doubt in the formation of 2,3-pentanedione, the partial or total overlap of the lowintensity absorption bands did not allow us to perform reliable subtraction results to proceed for its quantification. 2,3-Pentanedione exists predominantly in the keto form with the enol form being present to a few percent, at the most, in the gas phase at room temperature (Kung, 1974; Szabó et al., 2011). The predominance of the keto form for this compound makes its reactivity toward $\mathrm{OH}$ radicals much lower. Furthermore, in comparison with 2,4-pentanedione, a dicarbonyl compound having the enolic form predominantly and thus being more reactive toward $\mathrm{OH}$ radicals $\left(9.05 \times 10^{-11} \mathrm{~cm}^{3}\right.$ molecule $\left.{ }^{-1} \mathrm{~s}^{-1}\right)$ (Zhou et al., 2008), 2,3pentanedione, with a rate coefficient for the reaction with $\mathrm{OH}$ radicals of $2.25 \times 10^{-12} \mathrm{~cm}^{3}$ molecule $\mathrm{s}^{-1} \mathrm{~s}^{-1}$ (Szabó et al., 2011) is 40 times less reactive, and consequently the secondary reaction with $\mathrm{OH}$ radicals could be of less importance (Messaadia et al., 2015).

On the other hand, photolysis quantum yields for 2,3pentanedione using $\mathrm{XeF}$ (xenon flouride) laser radiation and 


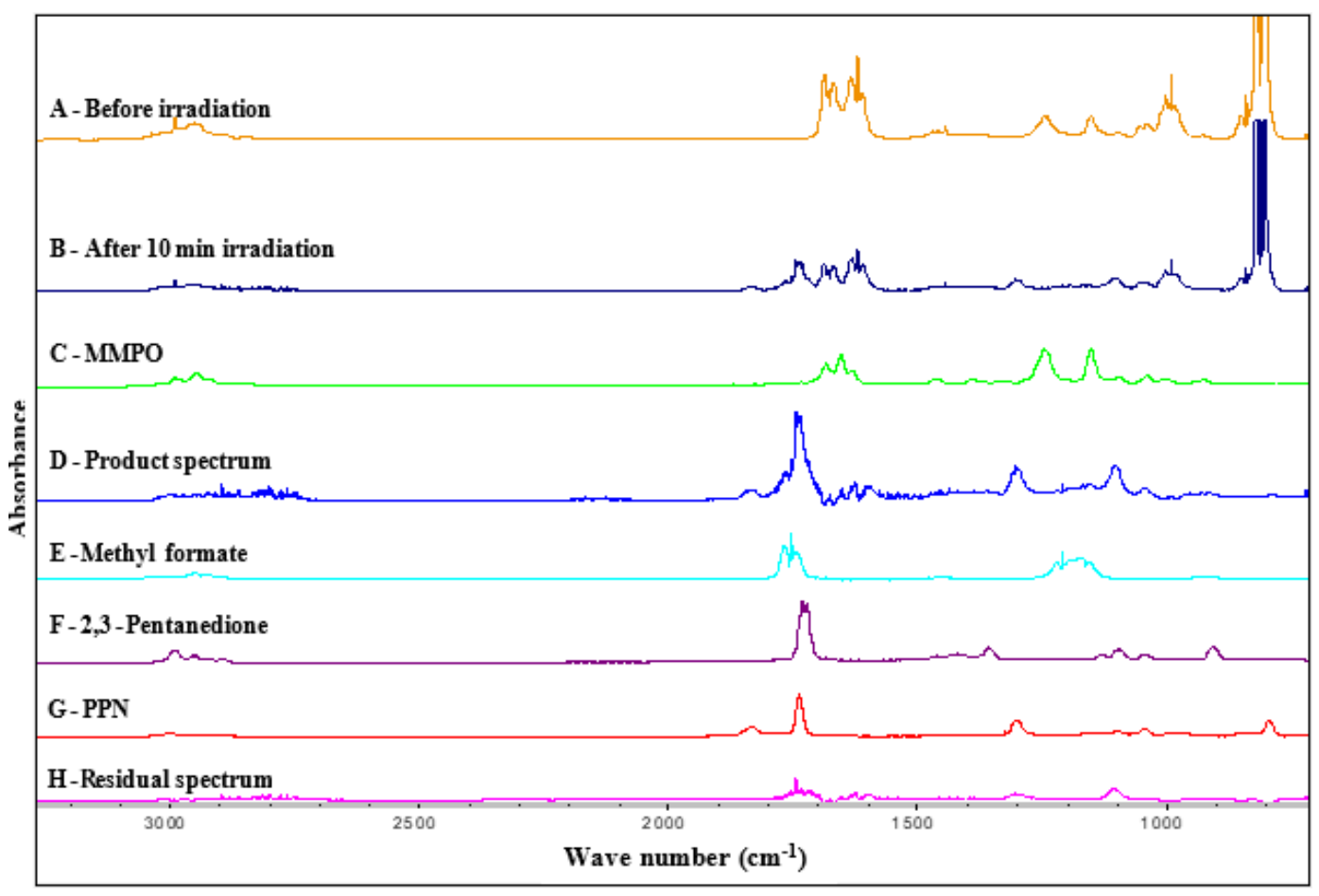

Figure 5. Infrared spectral data. Trace A: infrared spectrum of an $\mathrm{MMPO} / \mathrm{CH}_{3} \mathrm{ONO} /$ air reaction mixture before irradiation. Trace $\mathrm{B}$ : mixture after 10 min irradiation. Trace C: reference spectrum of MMPO. Trace D: product spectrum. Trace E: reference spectrum of methyl formate. Trace F: reference spectrum of 2, 3-pentanedione. Trace G: reference spectrum of PPN. Trace H: residual spectrum after subtraction of the identified reaction products in trace $\mathrm{D}$.

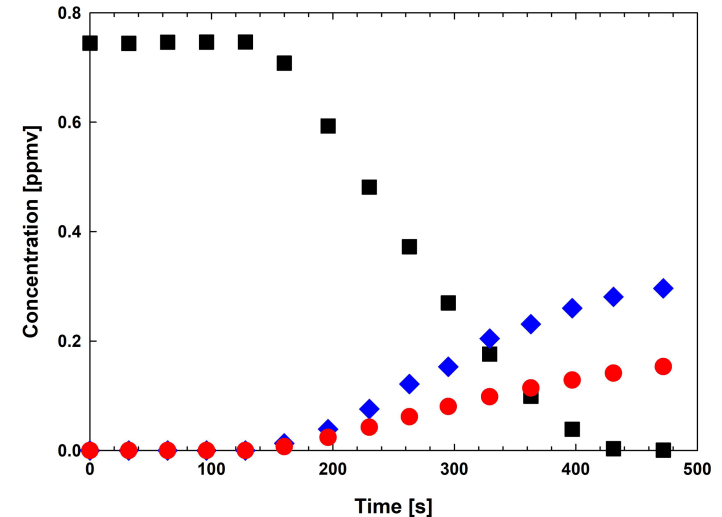

Figure 6. Concentration-time profiles for the reaction of MMPO (ם) $+\mathrm{OH}$ radicals and the quantified product of methyl formate $(\diamond \mathrm{MF})$ and peroxypropionyl nitrate (OPPN).

UV lamps at room temperature in 1000 mbar of air were studied by Szabó et al. (2011). The results obtained in their work suggest that 2,3-pentanedione would suffer significant photochemical changes even at relatively long wavelengths involving short photolysis lifetime in the troposphere. If we consider these facts, it would be possible to expect a nonnegligible photolysis of the compound in our experimental system under the conditions used for this study.
Decomposition of the A2 hydroxyalkoxy radical could follow the scission on route II leading to 1-hydroxy-1methoxypropan-2-one and a propionyl radical. 1-Hydroxy1-methoxypropan-2-one is not commercially available, and thus it is not possible to identify this compound by comparison with an infrared reference spectrum. However, the absorption band with the maximum at $3512 \mathrm{~cm}^{-1}$ could be assumed to the $\mathrm{O}-\mathrm{H}$ stretching band of 1-hydroxy1-methoxypropan-2-one (see Fig. S3). The infrared spectrum in Fig. S3 presents one main absorption feature that could be attributed to the O-H stretching of 1-hydroxy-1methoxypropan-2-one produced by the more stable tertiary radical $\left(A_{2}\right)$. The propionyl radical could further form peroxypropionyl nitrate (PPN) (Fig. 5, trace G) in the presence of $\mathrm{O}_{2}$ and $\mathrm{NO}_{2}$.

Plots of the concentrations of methyl formate and PPN formed against reacted MMPO in the $\mathrm{OH}$ radical reaction give molar formation yields of $(40 \pm 12) \%$ and $(17 \pm 6) \%$, respectively. The yields have been corrected for secondary reactions with $\mathrm{OH}$ radicals using the method outlined by $\mathrm{Tu}-$ azón et al. (1986). Exemplary plots of the product formation yields are shown in the Fig. S4. 


\section{Atmospheric implications and conclusions}

Once emitted into the atmosphere, it is expected that unsaturated ketoethers such as TMBO and MMPO will follow gas phase degradation processes initiated by the main tropospheric oxidants $(\mathrm{OH}$ radicals, ozone, chlorine atoms and $\mathrm{NO}_{3}$ radicals). Rate coefficients obtained in this work for the reaction of TMBO and MMPO with $\mathrm{OH}$ radicals were used to calculate their tropospheric lifetimes using the expression $\tau_{x}=1 / k_{\mathrm{O}_{x}}\left[\mathrm{O}_{x}\right]$, where $\left[\mathrm{O}_{x}\right]$ is the typical atmospheric concentration of the oxidant in the troposphere and $k_{\mathrm{O}_{x}}$ is the rate coefficient for the reaction of TMBO and MMPO towards the oxidants. Considering a $12 \mathrm{~h}$ daytime average $\mathrm{OH}$ radical concentration of $2 \times 10^{6}$ molecule $\mathrm{cm}^{-3}$ (global weightedaverage concentration) (Bloss et al., 2005), average lifetimes of 0.98 and $0.42 \mathrm{~h}$ were estimated for TMBO and MMPO, respectively. As mentioned before, in the literature there is only one experimental determination for the TMBO reaction rate coefficient with $\mathrm{O}_{3}$ performed by Grosjean et al. (1999). By using $k_{\mathrm{O}_{3}}=1.3 \times 10^{-16} \mathrm{~cm}^{3}$ molecule ${ }^{-1} \mathrm{~s}^{-1}$ and a $24 \mathrm{~h}$ average $\mathrm{O}_{3}$ concentration of $7 \times 10^{11}$ molecule $\mathrm{cm}^{-3}$ (Logan, 1985), an estimated tropospheric residence time of $3.1 \mathrm{~h}$ was calculated. A similar tropospheric lifetime is expected for MMPO towards ozone, but due to the lack of kinetic data, no exact value could be calculated for MMPO. Unfortunately, no kinetic data are available for the reactions of TMBO and MMPO with $\mathrm{Cl}$ atoms and $\mathrm{NO}_{3}$ radicals. However, it is reasonable to conclude that a reaction with $\mathrm{OH}$ radicals is the main tropospheric removal pathway during daytime for the two ketoethers studied due to the short lifetimes calculated in this work. For ethers it is known that photodissociation quantum yields are relatively low, and the photolysis of ketones becomes important only at high altitudes (Mellouki et al., 2015). Thus, it is reasonable to assume that photolysis of the studied compounds is only of minor importance for their atmospheric removal.

The reaction products of the $\mathrm{OH}$ radical initiated degradation of MMPO and TMBO confirm that the main degradation mechanisms follow the addition pathways to the double bonds. Products identified and quantified from these reactions are carbonyls like methyl formate, methyl glyoxal and 2,3-pentanedione and long-lived nitrogen containing compounds such as PAN and PPN. Both types of these oxygenated products could have a further impact on atmospheric processes. The present study proposes new gas phase contributors to the total budget of methyl glyoxal in the atmosphere, a well-known precursor for SOAs formation (Fu et al., 2008). Even more this study becomes important, since MMPO and TMBO are VOCs possibly released from open biomass-burning events whose emissions factors for methyl glyoxal are not well established (Zarzana et al., 2018). PAN and PPN, quantified also as reaction products, are phytotoxic air pollutants, which act as an $\mathrm{NO}_{x}$ reservoir in remote areas (Taylor, 1969). Beside a large number of PAN measurement campaigns, most recent chemical transport models still unsolved the PAN global distributions due to the lack of understanding of the PAN source attribution in the atmosphere (Fischer et al., 2014). Although the acetyl radical is intermediary in the formation of PAN in this study, by its acetyl peroxy radical formed in the presence of oxygen, this radical could play an important role in the $\mathrm{HO}_{x}$ balance over the low$\mathrm{NO}_{x}$ environment. The acetyl peroxy radical is a well-known precursor of $\mathrm{OH}$ radicals as a result of the reaction with $\mathrm{HO}_{2}$ in the remote atmosphere (Winiberg et al., 2016). Therefore, the gas phase mechanism proposed in this study could be of importance for understanding atmospheric processes at the global scale, either in the atmosphere with low $\mathrm{NO}_{x}$ levels or in the atmosphere with increased $\mathrm{NO}_{x}$. The results of the present study provide improved insights regarding the important contribution of multifunctional VOCs in the chemistry of the atmosphere.

Data availability. Data can be provided upon request to the corresponding authors: Rodrigo Gaston Gibilisco (gibilisco@uni-wuppertal.de) and Iustinian Gabriel Bejan (iustinian.bejan@uaic.ro).

Supplement. The supplement related to this article is available online at: https://doi.org/10.5194/acp-20-8939-2020-supplement.

Author contributions. RGG, IB, IGB and PW designed the experimental setup. RGG conducted the measurements. RG and IGB processed the data. RGG, IGB and PW prepared the paper with contributions from all the co-authors at different stages of the writing process.

Competing interests. The authors declare that they have no conflict of interest.

Acknowledgements. Rodrigo Gastón Gibilisco acknowledges the Alexander von Humboldt Foundation for providing a Georg Forster Research Fellowship. All the authors thank the EUROCHAMP2020 European project and the Deutsche Forschungsgemeinschaft (DFG). Iustinian Bejan thanks the UEFISCDI IGAC-CYCLO project.

Financial support. This research has been supported by the Alexander von Humboldt Foundation (grant no. ARG 1187109 GFP), the EUROCHAMP2020 project (grant no. 730997), and the UEFISCDI (grant no. PN-III-P4-ID-PCE-2016-0807).

Review statement. This paper was edited by James B. Burkholder and reviewed by two anonymous referees. 


\section{References}

Atkinson, R.: Atmospheric chemistry of VOCs and $\mathrm{NO}_{x}$, Atmos. Environ., 34, 2063-2101, https://doi.org/10.1016/S13522310(99)00460-4, 2000

Atkinson, R. and Aschmann, S. M.: Rate constants for the reaction of $\mathrm{OH}$ radicals with a series of alkenes and dialkenes at $295 \pm 1 \mathrm{~K}$, Int. J. Chem. Kinet., 16, 1175-1186, https://doi.org/10.1002/kin.550161002, 1984.

Atkinson, R., Baulch, D. L., Cox, R. A., Crowley, J. N., Hampson, R. F., Hynes, R. G., Jenkin, M. E., Rossi, M. J., Troe, J., and IUPAC Subcommittee: Evaluated kinetic and photochemical data for atmospheric chemistry: Volume II - gas phase reactions of organic species, Atmos. Chem. Phys., 6, 3625-4055, https://doi.org/10.5194/acp-6-3625-2006, 2006.

Blanco, M. B. and Teruel, M. A.: Atmospheric photodegradation of ethyl vinyl ketone and vinyl propionate initiated by $\mathrm{OH}$ radicals, Chem. Phys. Lett., 502, 159-162, https://doi.org/10.1016/j.cplett.2010.12.059, 2011.

Blanco, M. B., Barnes, I., and Wiesen, P.: Kinetic investigation of the $\mathrm{OH}$ radical and $\mathrm{Cl}$ atom initiated degradation of unsaturated ketones at atmospheric pressure and $298 \mathrm{~K}$, J. Phys. Chem. A, 116, 6033-6040, https://doi.org/10.1021/jp2109972, 2012.

Bloss, W. J., Evans, M. J., Lee, J. D., Sommariva, R., Heard, D. E., and Pilling, M. J.: The oxidative capacity of the troposphere: Coupling of field measurements of $\mathrm{OH}$ and a global chemistry transport model, Faraday Discuss., 130, 425-436, https://doi.org/10.1039/b419090d, 2005.

Calvert, J., Mellouki, A., Orlando, J. J., Pilling, M. J., and Wallington, T. J.: The Mechanisms of Atmospheric Oxidation of the Oxygenates, Oxford University Press, New York, 2011.

Calvert, J. G., Orlando, J. J., Stockwell, W. R., and Wallington, T. J.: The Mechanisms of Reactions Infuencing Atmospheric Ozone, Oxford University Press, 2015.

Cilek, J. E., Ikediobi, C. O., Hallmon, C. F., Johnson, R., Onyeozili, E. N., Farah, S. M., Mazu, T., Latinwo, L. M., Ayuk-Takem, L., and Berniers, U. R.: Semi-field evaluation of several novel alkenol analogs of 1-octen-3-ol as attractants to adult Aedes albopictus and Culex quinquefasciatus, J. Am. Mosq. Control Assoc., 27, 256-262, https://doi.org/10.2987/10-6097.1, 2011.

Fischer, E. V., Jacob, D. J., Yantosca, R. M., Sulprizio, M. P., Millet, D. B., Mao, J., Paulot, F., Singh, H. B., Roiger, A., Ries, L., Talbot, R. W., Dzepina, K., and Pandey Deolal, S.: Atmospheric peroxyacetyl nitrate (PAN): A global budget and source attribution, Atmos. Chem. Phys., 14, 2679-2698, https://doi.org/10.5194/acp-14-2679-2014, 2014.

Fu, T. M., Jacob, D. J., Wittrock, F., Burrows, J. P., Vrekoussis, M., and Henze, D. K.: Global budgets of atmospheric glyoxal and methylglyoxal, and implications for formation of secondary organic aerosols, J. Geophys. Res.-Atmos., 113, D15303, https://doi.org/10.1029/2007JD009505, 2008.

Gaona-Colmán, E., Blanco, M. B., and Teruel, M. A.: Kinetics and product identification of the reactions of $(E)$-2-hexenyl acetate and 4-methyl-3-penten-2-one with $\mathrm{OH}$ radicals and $\mathrm{Cl}$ atoms at $298 \mathrm{~K}$ and atmospheric pressure, Atmos. Environ., 161, 155-166, https://doi.org/10.1016/j.atmosenv.2017.04.033, 2017.

Gøgsig, T. M., Nielsen, D. U., Lindhardt, A. T., and Skrydstrup, T.: Palladium catalyzed carbonylative Heck reaction affording monoprotected 1,3-ketoaldehydes, Org. Lett., 14, 2536-2539, https://doi.org/10.1021/ol300837d, 2012.
Green, M., Yarwood, G., and Niki, H.: FTIR study of the Cl-atom initiated oxidation of methylglyoxal, Int. J. Chem. Kinet., 22, 689-699, https://doi.org/10.1002/kin.550220705, 1990.

Grosjean, E. and Grosjean, D.: The reaction of unsaturated aliphatic oxygenates with ozone, J. Atmos. Chem., 32, 205-232, https://doi.org/10.1023/A:1006122000643, 1999.

Hatch, L. E., Luo, W., Pankow, J. F., Yokelson, R. J., Stockwell, C. E., and Barsanti, K. C.: Identification and quantification of gaseous organic compounds emitted from biomass burning using two-dimensional gas chromatography-time-offlight mass spectrometry, Atmos. Chem. Phys., 15, 1865-1899, https://doi.org/10.5194/acp-15-1865-2015, 2015.

Holloway, A. L., Treacy, J., Sidebottom, H., Mellouki, A., Daële, V., Le Bras, G., and Barnes, I.: Rate coefficients for the reactions of $\mathrm{OH}$ radicals with the keto/enol tautomers of 2,4pentanedione and 3-methyl-2,4-pentanedione, allyl alcohol and methyl vinyl ketone using the enols and methyl nitrite as photolytic sources of OH, J. Photochem. Photobiol. A, 176, 183190, https://doi.org/10.1016/j.jphotochem.2005.08.031, 2005.

Jiménez, E., Cabañas, B., and Lefebvre, G.: Environment, Energy and Climate Change I, in: The Handbook of Environmental Chemistry, Springer, 2014.

Kumar, N. R., Poornachandra, Y., Swaroop, D. K., Dev, G. J., Kumar, C. G., and Narsaiah, B.: Synthesis of novel ethyl 2,4disubstituted 8-(trifluoromethyl)pyrido[2',3' $: 3,4]$ pyrazolo[1,5a]pyrimidine-9-carboxylate derivatives as promising anticancer agents, Bioorg. Med. Chem. Lett., 26, 5203-5206, 2016.

Kung, J. T.: New caramel compound from coffee, J. Agr. Food Chem., 22, 494-496, 1974.

Li, M., Liu, Y., and Wang, L.: Gas-phase ozonolysis of furans, methylfurans, and dimethylfurans in the atmosphere, Phys. Chem. Chem. Phys., 20, 24735-24743, https://doi.org/10.1039/c8cp04947e, 2018.

Logan, J. A.: Tropospheric ozone: seasonal behavior, trends, and anthropogenic influence, J. Geophys. Res., 90, 10463-10482, https://doi.org/10.1029/JD090iD06p10463, 1985.

Lv, C., Du, L., Tsona, N., Jiang, X., and Wang, W.: Atmospheric Chemistry of 2-Methoxypropene and 2-Ethoxypropene: Kinetics and Mechanism Study of Reactions with Ozone, Atmosphere (Basel), 9, 1-14, 2018.

Mellouki, A., Le Bras, G., and Sidebottom, H.: Kinetics and Mechanisms of the Oxidation of Oxygenated Organic Compounds in the Gas Phase, Chem. Rev., 103, 5077-5096, https://doi.org/10.1021/cr020526x, 2003.

Mellouki, A., Wallington, T. J., and Chen, J.: Atmospheric Chemistry of Oxygenated Volatile Organic Compounds: Impacts on Air Quality and Climate, Chem. Rev., 115, 3984-4014, https://doi.org/10.1021/cr500549n, 2015.

Messaadia, L., El Dib, G., Ferhati, A., and Chakir, A.: UV-visible spectra and gas-phase rate coefficients for the reaction of 2,3-pentanedione and 2,4-pentanedione with $\mathrm{OH}$ radicals, Chem. Phys. Lett., 626, 73-79, https://doi.org/10.1016/j.cplett.2015.02.032, 2015.

Szabó, E., Djehiche, M., Riva, M., Fittschen, C., Coddeville, P., Sarzyński, D., Tomas, A., and Dóbé, S.: Atmospheric chemistry of 2,3-pentanedione: Photolysis and reaction with $\mathrm{OH}$ radicals, J. Phys. Chem. A, 115, 9160-9168, https://doi.org/10.1021/jp205595c, 2011. 
Taylor, O. C.: Importance of peroxyacetyl nitrate (pan) as a phytotoxic air pollutant, J. Air Pollut. Control Assoc., 19, 347-351, https://doi.org/10.1080/00022470.1969.10466498, 1969.

Taylor, W. D., Allston, T. D., Moscato, M. J., Fazekas, G. B., Kozlowski, R., and Takacs, G. A.: Atmospheric photodissociation lifetimes for nitromethane, methyl nitrite, and methyl nitrate, Int. J. Chem. Kinet., 12, 231-240, https://doi.org/10.1002/kin.550120404, 1980.

Tuazon, E. C., Leod, H. Mac, Atkinson, R., and Carter, W. P.: $\alpha$ Dicarbonyl Yields from the $\mathrm{NO}_{x}$-Air Photooxidations of a Series of Aromatic Hydrocarbons in Air, Environ. Sci. Technol., 20, 383-387, https://doi.org/10.1021/es00146a010, 1986.

US EPA: Estimation Programs Interface Suite ${ }^{\mathrm{TM}}$ for Microsoft ${ }^{\circledR}$ Windows, v 4. 11. E. P. A., AOPWIN, 2018.

Vereecken, L., Aumont, B., Barnes, I., Bozzelli, J. W., Goldman, M. J., Green, W. H., Madronich, S., Mcgillen, M. R., Mellouki, A., Orlando, J. J., Picquet-Varrault, B., Rickard, A. R., Stockwell, W. R., Wallington, T. J., and Carter, W. P. L.: Perspective on Mechanism Development and Structure-Activity Relationships for GasPhase Atmospheric Chemistry, Int. J. Chem. Kinet., 50, 435-469, https://doi.org/10.1002/kin.21172, 2018.
Villanueva, F., Cabañas, B., Monedero, E., Salgado, S., Bejan, I., and Martin, P.: Atmospheric degradation of alkylfurans with chlorine atoms: Product and mechanistic study, Atmos. Environ., 43, 2804-2813, https://doi.org/10.1016/j.atmosenv.2009.02.030, 2009.

Winiberg, F. A. F., Dillon, T. J., Orr, S. C., Groß, C. B. M., Bejan, I., Brumby, C. A., Evans, M. J., Smith, S. C., Heard, D. E., and Seakins, P. W.: Direct measurements of $\mathrm{OH}$ and other product yields from the $\mathrm{HO}_{2}+\mathrm{CH}_{3} \mathrm{C}(\mathrm{O}) \mathrm{O}_{2}$ reaction, Atmos. Chem. Phys., 16, 4023-4042, https://doi.org/10.5194/acp16-4023-2016, 2016.

Zarzana, K. J., Selimovic, V., Koss, A. R., Sekimoto, K., Coggon, M. M., Yuan, B., Dubé, W. P., Yokelson, R. J., Warneke, C., De Gouw, J. A., Roberts, J. M., and Brown, S. S.: Primary emissions of glyoxal and methylglyoxal from laboratory measurements of open biomass burning, Atmos. Chem. Phys., 18, 15451-15470, https://doi.org/10.5194/acp-18-15451-2018, 2018.

Zhou, S., Barnes, I., Zhu, T., Klotz, B., Albu, M., Bejan, I., and Benter, T.: Product study of the $\mathrm{OH}, \mathrm{NO}_{3}$, and $\mathrm{O}_{3}$ initiated atmospheric photooxidation of propyl vinyl ether, Environ. Sci. Technol., 40, 5415-5421, https://doi.org/10.1021/es0605422, 2006.

Zhou, S., Barnes, I., Zhu, T., Bejan, I., Albu, M., and Benter, T. Atmospheric chemistry of acetylacetone, Environ. Sci. Technol., 42, 7905-7910, https://doi.org/10.1021/es8010282, 2008. 